\title{
Eco-Revelatory Design
}

\author{
Nurgül Konaklı Arısoy
}

Additional information is available at the end of the chapter

http://dx.doi.org/10.5772/55764

\section{Introduction}

Built environments ignore people's need and their potential for learning. The negative effects related to the ignorance of natural systems in human development are evident. Making natural cycles and processes visible bring the designed environment back to life. Effective design helps inform us of our place within nature. Landscape architects have developed theories and methodologies which represent a new, ecologically oriented approach to design.

Eco-revelatory design (ERD) is an ecological design concept in the field of landscape architecture means "a design strategy that attempts to enhance site ecosystems as well as engage users by revealing ecological and cultural phenomena, processes and relationships affecting a site " [1]. Landscape architects reveal nature through their form, materials and formation, and they also reveal the nature of the person who designed them. ERD is a new approach to landscape architecture, one where ecological processes and the environment is a fundamental determinant of the design.

ERD is a different exposition and interpretation -updated version- of design. It is an integrative and ecologically responsible design. It is a partnership between people and nature. ERD attempts to enhance site ecosystems and engage users by revealing ecological and cultural phenomena, processes, and relationships affecting a site. It aspires to reveal endemic ecological process and affords a more direct connection between fundamental ecological process and the phenomenological experience of landscape. It is important to involve using knowledge about how interact with environment to form objects and spaces with skill and artistry [4]. This approach to design should be applied not only to urban sides, but also to nonurban sides such as wetlands, arboretums. The theory has received heavy criticism about its ability to absorb an audience in ecological understanding or improve site conditions [2,3].

Another criticism about ERD is some designs make tangible improvements in local ecological health while others are symbolic gestures [2]. It is adequate for people to develop 
ecological perception by means of the visibility of ecological process in design. The theory has received heavy criticism about its ability to absorb an audience in ecological understanding or improve site conditions.

It aspires to reveal endemic ecological process and affords a more direct connection between fundamental ecological process and the phenomenological experience of landscape. It is important to involve using knowledge about how interact with environment to form objects and spaces with skill and artistry (Ndubisi, 2002). This approach to design should be applied not only to urban sides, but also to non-urban sides such as wetlands, arboretums.

They are typically designed landscapes that elucidate natural phenomenon such as the cleansing action of wetlands. Ecorevelatory landscapes have also been referred to as "educational and enlightening". They are reference sites for what we understand about our environment and its workings. Designs can convey knowledge through direct experience as well as by interpretation. Interpretation seeks to create connections between the resources that are being interpreted and relevant everyday knowledge that everyone has by engaging emotions, creating experiences, and entertaining ideas through engagement [5]. By highlighting the particular ecological relationships at any given site, such design can punctuate and enliven our environment and sensitize us to what is known about its interlocking complexities" [1]. These sites often still use traditional interpretive media such as wayside exhibits and publications to fully convey their meaning and function, but ecorevelatory design can bring to light processes that usually remain unseen and forgotten.

\section{History}

This study explores descriptive theory, principals, techniques and practice of eco-revelatory design, can help to plan a sustainable development, which uses and reveals natural systems to reconciling human systems and its effects on the surrounding environment. The goal of this study, therefore, is to generate ideas and to begin a discussion about how the design within an eco-revelatory framework will be.

Most of the "eco" prefixes such as eco-city, eco-technique, eco-efficient was began to used nineties; also ERD emerged in 1998 as a new theory within the field of landscape architecture.

The term and practice of ERD was coined from an exhibit Nature Constructed/Nature Revealed sponsored by the University of Illinois at Urbana-Champaign. Two predominant schools of thought, one insistently cultural and the other assertively ecological, reigned over the conceptual and theoretical dialog in landscape design and planning. In 1998 a group of practitioners and landscape scholars published a special issue of Landscape Journal as a catalogue and record of the exhibition Eco-Revelatory Design: Nature Constructed/Nature Revealed. Brenda Brown, Terry Harkness, and Douglas Johnston chaired the exhibition and served as guest editors of the journal (Figure 1). The exhibit opened at the University of Illinois in 1998 and closed at the Washington DC's National Building Museum in 2000.

Brown identifies three areas of investigation on landscapes as/of sound: listening gardens, sound, or listening trails, and sound designs [3]. She is particularly interested in what she 
calls "the reciprocal revelations of landscapes and sounds, how sounds can reveal landscapes and how landscapes can reveal sounds." She is therefore also concerned with how people perceive, understand and engage with landscapes.

ERD roots are based on ecologically minded landscape architects such as Ian McHarg and Frederick Law Olmsted but they didn't use the term as ERD. These landscape architects created works to foster function in natural systems and processes aesthetically. Ian McHarg was accepted as the first person who to apply his ecological knowledge into design. He began advocating the use of ecology as a basis for design in the early 1960s. He accomplished his goal of merging design with ecology. He gave importance of ecological principles in design.

Thirty years ago, in Design with Nature, McHarg proposed a system of ecological inventories to help explain the way natural processes may influence regional and urban planning and design [6]. Also, it makes the case for an ecological approach to design. McHarg gave a new dimension to the historical goal of 'imitating nature' (mimesis). He was concerned both with

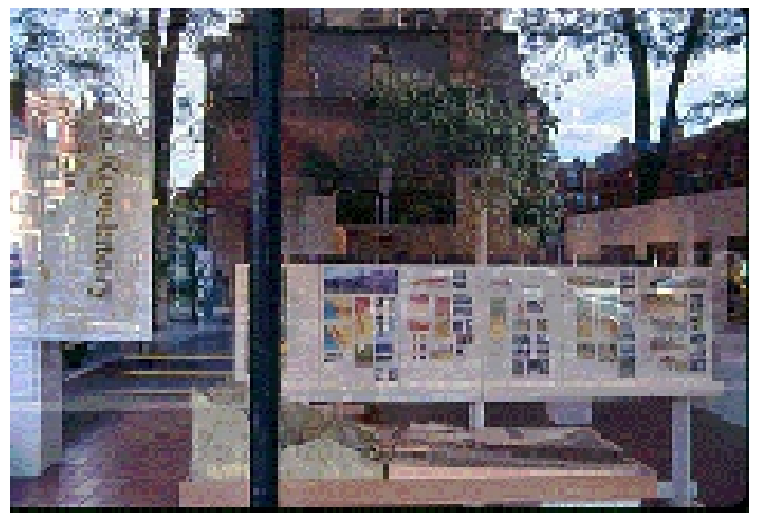

Figure 1. Eco-revelatory design exhibit

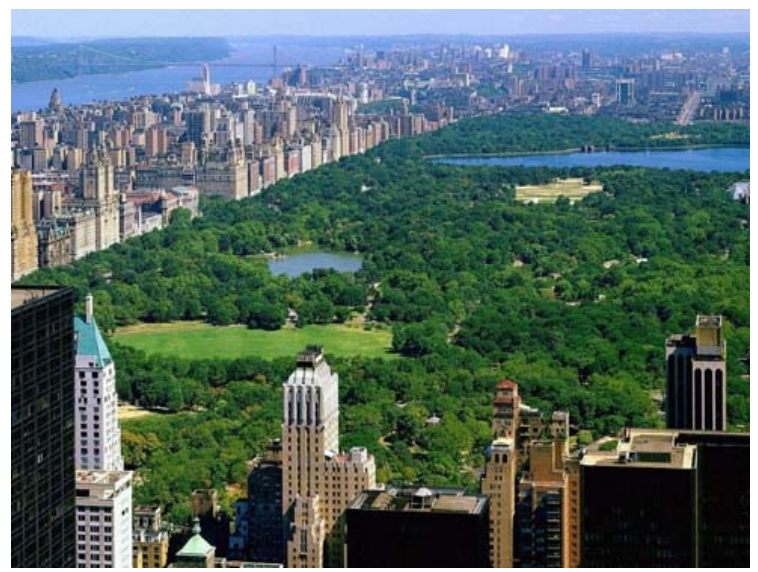

Figure 2. Central Park, NYC 
the practicalities of 'design with nature' and with the aesthetic results of a naturalist approach to landscape and garden design. It was demanded that local landscapes should follow ecological principles that implied that landscape could not represent some particular claim of social identity.

In the second half of the 19th century, Frederick Law Olmsted completed a series of parks which continue to have a huge influence on the practices of Landscape Architecture today. Among these were Central Park in New York City (Figure 2), Prospect Park in Brooklyn (Figure3), New York and Boston's Emerald Necklace park system (Figure 4).

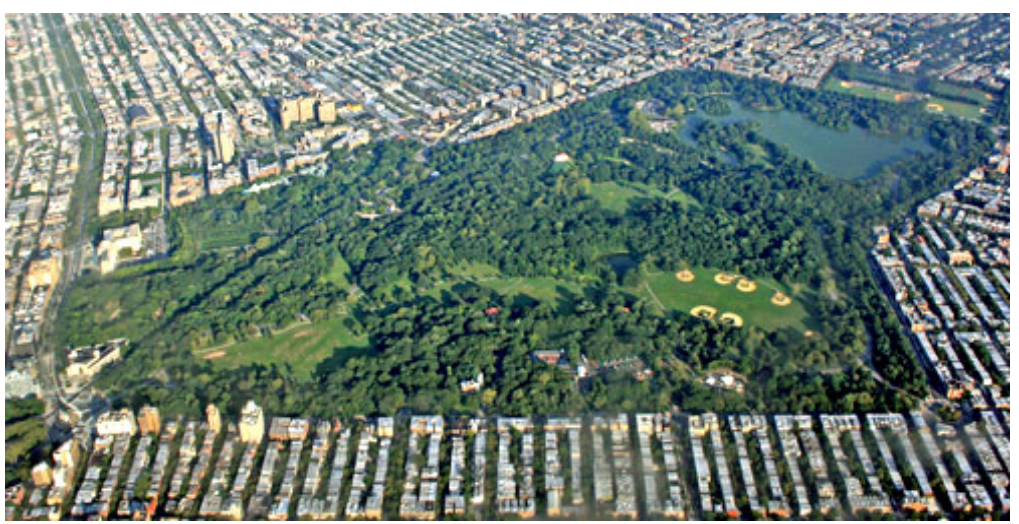

Figure 3. Prospect Park in Brooklyn

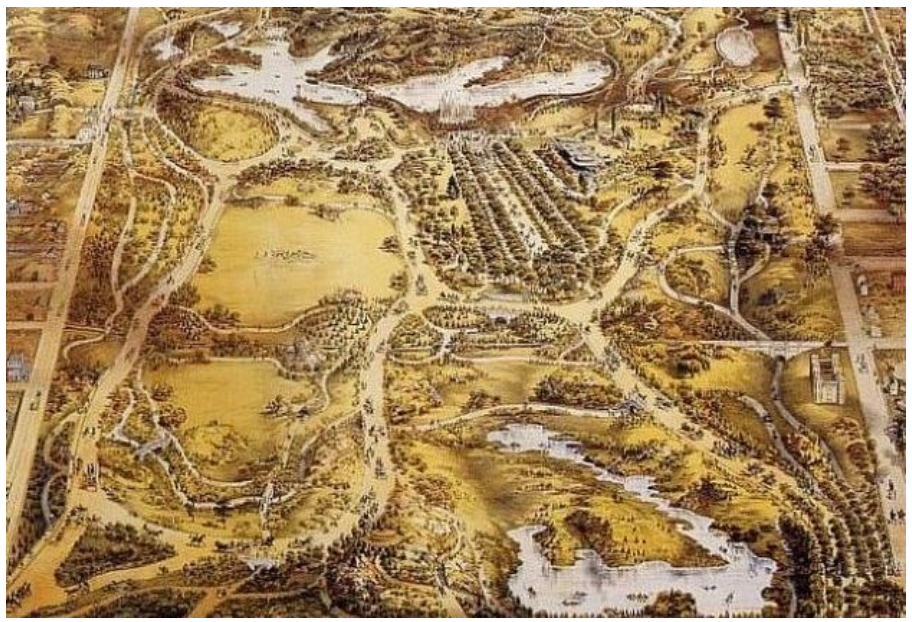

Figure 4. Boston's Emerald Necklace park system

The Emerald Necklace consists of a 1,100-acre $\left(4.5 \mathrm{~km}^{2}\right)$ chain of parks linked by parkways and waterways in Boston and Brookline, Massachusetts. 
Several components of the Emerald Necklace pre-date the plan to unite them. Some links of the Emerald Necklace not only offer an opportunity for recreation in a wooded environment, but are also ecologically important urban wilds that provide nesting places for migratory birds, fishes and other animals and improve the air quality of the city. The Emerald Necklace Project successfully ties together conservation, land restoration, sewage treatment, solid waste disposal, recreation, transportation, and water and visual quality [7]. The park system provides opportunities for people to learn about natural systems by enjoying, observing, and appreciating these systems.

Today, landscape architects recognize the effects of ignorance on natural systems in human development. So they coined a new design approaches.

Arcata Marsh is one of the ERD examples of today design approach. The Arcata Marsh and Wildlife Sanctuary was constructed in 1981 (Figure 5). The City of Arcata incorporated wastewater treatment to the system in 1986. The City of Arcata's unique wastewater treatment facility, marsh, and wildlife sanctuary attracts approximately 150,000 visitors per year [8]. Arcata's wastewater treatment plant is an example of a community involvement in environmental politics, innovative uses of land, and applications of appropriate technology in a small urban community. The Arcata Wastewater Treatment Plant combined with the Arcata Marsh and Wildlife Sanctuary has multiple uses, including wastewater treatment, recreation, wildlife habitat, education, and research. The residents of Arcata who stroll by the wetland can, for instance; see that wastewater treatment wetlands can be important habitat for fish and birds, as well as an energy-efficient, biologically based method of controlling water pollution. The experience of the Arcata wetland shows that ecological processes can be brought into a constructive partnership with human settlements.
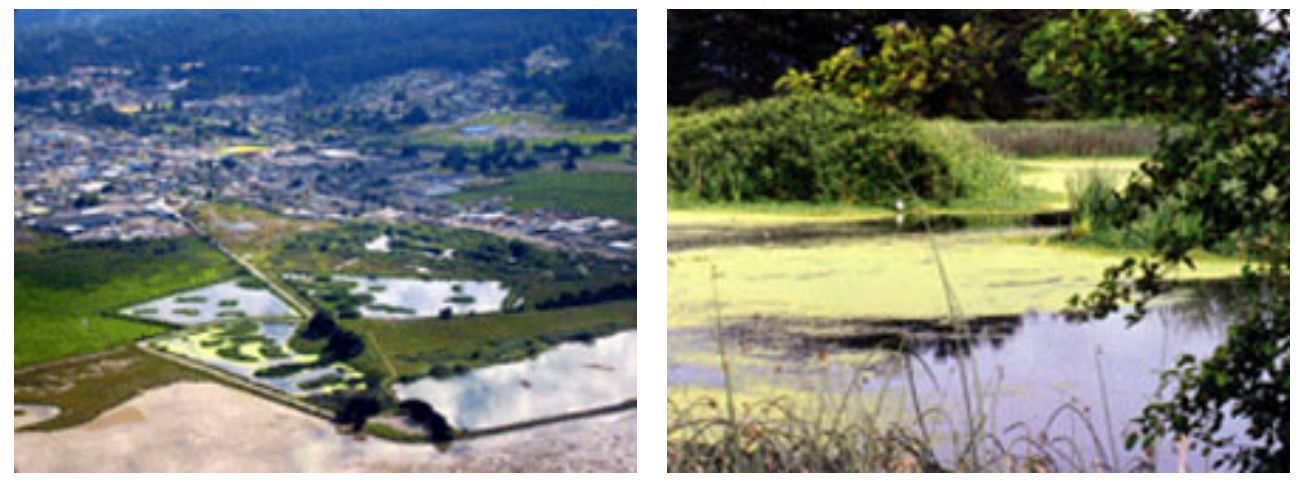

Figure 5. The Arcata Marsh and Wildlife Sanctuary (source: http://www.humboldt.edu/engineering/graduate/facilities)

Students are centrally involved in the original design and development of the Marsh's constructed wetland water treatment system, and they continue to play a key role through projects and research geared towards the continued optimization of the system. 
The second example for ERD is the Gateway Business Center - post-industrial area- is a 25acre site consisting of 10 industrial tilt-up buildings located at the San Gabriel Mountain foothills on a great alluvial fan that crosses the San Gabriel Valley on its way to the Pacific Ocean. The site concept transformed an industrial building environment into a sustainable and nature-inspiring experience. The layout of cairns act as way finding and directional markers and add to the overall landscape display and experience of bioswales, infiltration zones, rain harvesting, solar canopies and an array of recycled materials.

The site landscape is designed to mimic the natural feel of the local native landscape character and capture it into the renovated industrial complex. The goal is to create "biophilia" (an instinctive bond between man and nature). The bioswale has taken the place of the previous concrete swale, while the concrete catch basin remains to collect any additional runoff in a deluge, and as a reminder of the previous form of site storm water drainage. More than 95 percent of the runoff water in this parking lot is captured.

The storm garden is irrigated by the adjacent rain harvesting tanks. A natural wash picks up excess rainwater and roof water not captured by the parking lot bioswale. [9] (Figure 6)

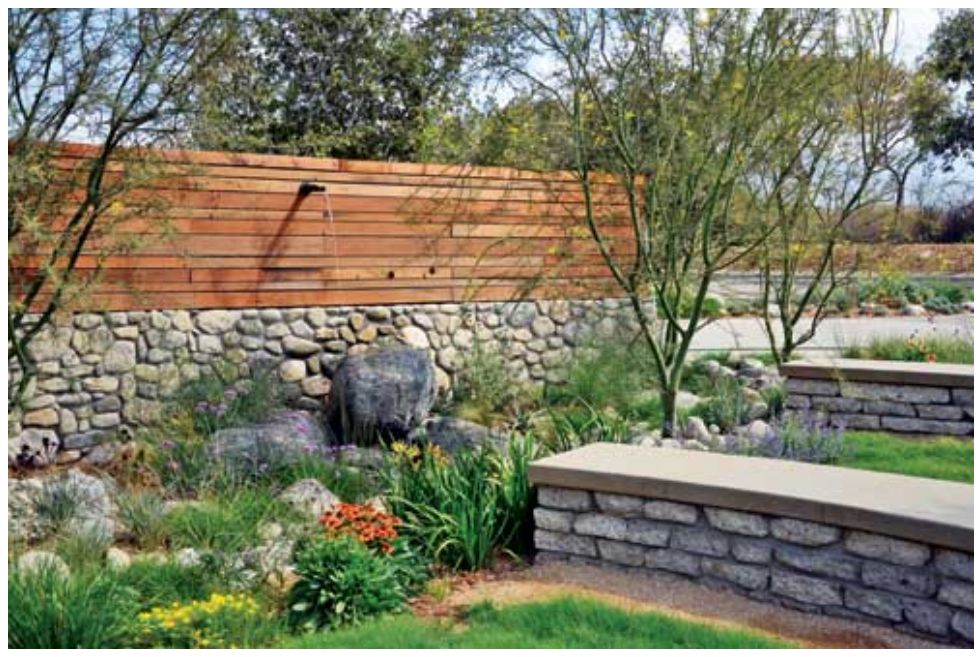

Figure 6. The Storm Garden of Gateway Business Center

\section{Design and ecology relationship}

Design is the intention that redefines how we relate to each other and our environment. The process of designing places and artefacts are opportunities to reimagine a new relationship with our environment, especially when it seems remote or difficult to create. Design that reveals hidden systems, whether ecological or economic, is a powerful way to meet the challenges of ecologically benign communities. Landscape design is a discipline which transfer the knowledge developed in landscape ecology to application [10]. 
The term ecology, like the term landscape, has multiple meanings. Ecology has historically focused on pristine, natural environments, however, by the 1970's many ecologists began to turn their interest towards the ecological interactions taking place in, and caused by urban environments. Urban ecology is recognized as a diverse and complex concept which differs in application between North America and Europe. The European concept of urban ecology examines the biota of urban areas while to the North American concept which has traditionally examined the social sciences of the urban landscape as well as the ecosystem fluxes and processes.

Environmental knowledge have been part of the intent of design in landscape architecture and various conceptions and methodologies have been improved for measuring the environmental consequences of design.

Nassauer and Opdam define design as intentional change of landscape pattern, for the purpose of sustainably providing ecosystem services while recognizably meeting societal needs and respecting societal values [11]. Design is both a product, landscape pattern changed by intention, and the activity of deciding what that pattern could be.

Ecology plays a big role in ERD. Disciplines in applied ecology such as urban ecology, landscape ecology etc. helps planning and design practice in landscape architecture. These disciplines help put theories into practice. The most important thing is to find how to use ecological thinking in design.

\section{Landscape architecture and landscape ecology}

Landscape architecture is informed by scientific knowledge and aspires to provide aesthetic expressions in landscapes across a range of spatial scales. Landscape ecology has been defined as the study of the effect of landscape pattern on process, in heterogeneous landscapes, across a range of spatial and temporal scales [12]. The logical reasons for integrating these two fields are clear and compelling, with a great potential to support sustainable landscapes through ecologically based planning and design.

Proponents of ERD recognized that landscape architecture alters and directs both cultural and ecological systems. Furthermore, they acknowledged landscape architects' capacity to direct human experience and reveal, through design, aspects of ecology and culture. This integrated approach provides opportunity for people to place themselves in and as part of an interconnected socio-ecologic world, reinforcing the relationships between humans and the bio-geosphere.

Landscape ecology is defined as a problem-oriented science [13]. It has developed from the growing awareness of environmental problems since the nineteen seventies. Spatial planning and landscape design are disciplines which transfer the knowledge developed in landscape ecology to application. To optimize this process of knowledge transfer, landscape ecology must co-evolve with spatial planning [14]. The development of ecologically sustainable landscapes requires that patterns of future landscapes sustain the necessary 
ecological processes in the landscape. Therefore, we must know how landscape patterns relate to these processes.

Humans are the driving force behind urban ecology and influence the environment in a variety of ways, such as modifying and altering land surfaces and waterways, introducing foreign species. In this context, changes between human-environment affect the styles of landscape design directly.

However, the present concept of ecological design and its interpretation in this sense does not refer to information charts or written explanations, which people encounter at places like zoological gardens or arboretums.

Generally, "ecological designs blend with their contexts and results in a diffuse visual pattern" [15]. Consequently, this perceptual subtlety can make ecological landscapes difficult for inhabitants to recognize and care about. ERD make ecological considerations perceivably a "visible part of landscape experience". It achieve this is by benefiting from the contrast between cultural and ecological domains. One way to achieve this is by exploiting the power of contrast, particularly the contrast between cultural and ecological domains. Ecological design has tended to diffuse edges to provide transition.

We can use basic principles of landscape ecology in landscape design. Such as linear parks, neighbourhood parks, playgrounds as for patch, greenways for corridor.

Every human directly or indirectly contributes towards enriching as well as degrading the quality and experience of cities. In order to create a successful ecological design it is important to recognize and interpret the historic and cultural significance of the landscape. In other words, "eco-revelatory design expands by hitching human habitat and their inevitable cultural determinants in to an environmentally inclusive vision" [16].

Farina observed that landscape design is an important component in practical landscape ecology as it expresses the relationship of spatial patterns and processes in a practical manner [17]. It provides in depth understanding on wildlife habitats and movements and biological interdependency within a region. The two disciplines should be complementary [17].

People use land for its scenic and recreational uses. Thus, the aesthetic use is important for them. However, natural systems are the important part of the designing decisions.

It is important to understand the social and cultural backgrounds and expectations of the society who use the land are determinant. It depends on two factors [18], in how people experience and use their landscapes, and their understanding of ecological processes.

It is important to organize a linkage between cultural expectations and ecological process. Man made land uses affect the ecological system activities such as wildlife crossing and subsurface water movement. Lyle has explained the following six basic ecological processes that are vital for operational integrity of natural systems [19].

In order to participate creatively in natural processes and to do so with reasonable hope of success, we need to include as subject of design the inner workings of the landscape, the 
systems that motivate and maintain it, and reveal them through creative, imaginative, and visible form of the landscape [19].

\section{Theory}

A design theory is a procedure for how to set about a design project. The classical twentieth century approach to landscape design has been Survey-Analysis- Design (SAD). It has been elevated to the status of a design methodology and cruelly overworked. The resultant places lacked clarity of intention. The intention of ERD is to "connect people with the natural environment". A dynamic balance between natural environment and society, intended to reveal and interpret (resolve and educate the relationship between user and the designed area ) and finally to provide awareness on ecological understanding.

Most of the landscape designers' style ignores natural systems and have only one purpose, primarily focused on aesthetics. ERD has to combine aesthetics and science. It is one of the endeavours that contribute to rediscovering aesthetics. It is hard to measure aesthetics outcome statistically or collectively. But can measure the environmental effects in numbers. So you can measure the sustainability by its effects on environment not by aesthetics.

\section{Method}

It is important to choose a method that is most compatible design strategy. It depends on the design intent, the place and the designer. How methods fit into design process should be determined clearly.

Generally two methods are used at ERD as follows;

a. Mimic the nature

b. Use the nature

a. We need to design a natural area to show the ecological processes and relationships. Artificial waterfalls can perfectly mimic the nature a way that highlight the system of the real one (Figure 7). Native trees and shrubs mimic the adjacent natural areas. The site landscape is designed to mimic the natural feel of the local native landscape character.

b. ERD utilizes the natural capabilities of the environment. In an ecorevelatory approach the pre-existing natural, structural and functional characteristics of the place are integrated into design and made them observable and understandable.

There are a lot of methods for ERD that landscape architecture can use such as environmental method, man centred method, evaluation method, interpretive analogy method. The design method is up to designer's idea and knowledge.

Through our senses, we form concrete relationships, we reconciliate, with the world. With this understanding, phenomenology can be used as a method for eco-revelatory design. Suitability analysis is also one of the approaches for ERD. 


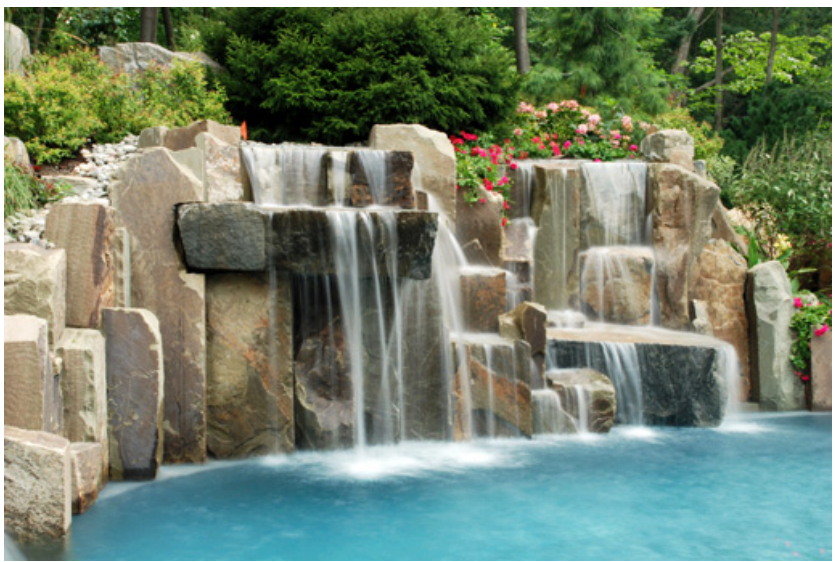

Figure 7. Artificial Waterfalls

\section{Design process}

When we examine the literature about ERD we can't see any knowledge about the design process. Landscape ecology principles integrate to design process. How can we adopt the ecology approach and principles into design process? We can use basic principles of landscape ecology in landscape design such as linear parks, neighbourhood parks, playgrounds as for patch, greenways for corridor. Landscape ecology principles influence every stage of landscape design process such as site planning.

One of the design processes is traditional design process that landscape architects undertake. It typically starts with the selection of a site based on a set of criteria. Once a site is selected, the typical design process will move through a series of phase including site inventory, site analysis, conceptual design, design development, construction documentation and finally implementation [20].

Landscape designers need to understand how natural and human systems work and design as an integral part of a nature and establish relationship with nature. They can achieve this by combining those with new technology to meet changing cultural and ecological needs.

\section{Principles (Design strategy)}

The hosts of the exhibit, Barbara Brown, Terry Harkness and Doug Johnston, take great care in describing what deserves to be called eco-revelatory design, and stressed stringent and ambitious goals for the competition. Those chosen for the exhibit represent rigorous application of eco-revelatory design, and utilize some or all of the following strategies [1]:

- Abstraction and simulation of natural processes

- New uses of landscapes producing deeper caring for life and ecological processes

- Signifying features that speak for natural/cultural processes that might otherwise remain invisible 
- $\quad$ Expose infrastructure and process

- Reclaim landscapes so that the past is remembered

- Change perspectives by structuring how we interact with the Landscape.

Interpretation of ecological processes refers to the ability of the design to reveal ecological processes at work. This process of revealing can only be successful if the environments created are visible, observable, legible, and have the ability to raise curiosity in visitors to explore and understand the complexity of the landscape. Principles for ERD are described generally as follows:

\section{Visibility}

Visibility is a cardinal point for ERD. Many designers and planners have become concerned in recent years with "revealing" ecological processes in their designs so that the users of the environment may experience, learn about, and appreciate those processes. In practice, "revelation" of ecological process has meant everything from capturing stormwater on the surface of the land before it drains away to the storm sewers. In addition, the ecological processes that are revealed may themselves be truly "natural," in the sense that they could continue to exist without the management of humans, or they may be highly artificial, engineered systems that need constant supervision if they are to persist in an urbanized context.

"Most of the time, natural systems themselves are not visible and readily engaging. What are visible are the surface manifestations and the material conclusions of these natural systems, for example layers of rocks are not ecological process, but the result of it" [21]. Thus the most important challenge for designers is to recognize which ecological processes can actually be made visible and how they can interpret these dynamic processes or their material conclusions to form and inform landscapes.

The Arcata Marsh and Wildlife Sanctuary, a real-world example of eco-revelatory design, highlights some of the positive potential of using visibility as a design strategy (Figure 8).

Some ERDs, for example, have sought to bring ecological processes (such as water flows) into the open, but then blend them in with the surrounding landscape as much as possible. Many proposals to capture rainfall in grassy areas and infiltrate it into the soil before it runs off into the storm sewers would use either parks or front lawns for this purpose. Although this strategy reveals an ecological process occurring during and just after a rainfall, the rest of the time these spaces would simply look like what they have always looked like--large grassy expanses--and would forfeit an opportunity to communicate a clear, consistent, and meaningful landscape message. Making natural cycles and processes visible bring the designed environment back to life.

In reference [22] the quantitative interpretation challenges aesthetics by rendering it negative, segregated and unstable. Under this "hegemony" various endeavours in which eco-revelatory design played a part involved in. It is important for people to "read" or "experienced" the ecological knowledge tried to given. This attempt is achieved by visibility. 


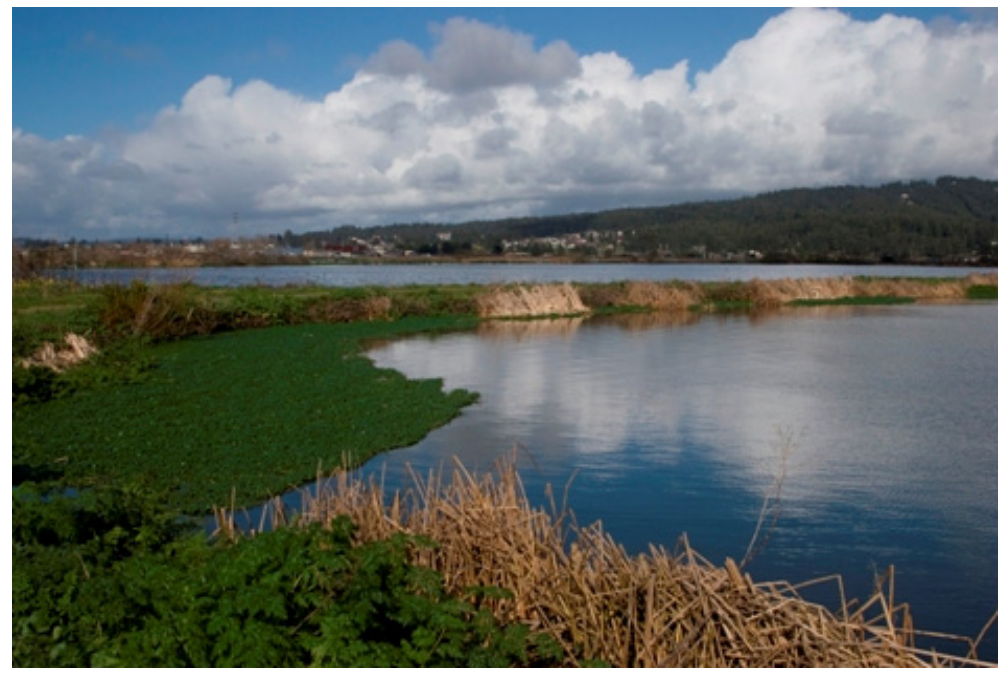

Figure 8. An Oxidation Pond at the Arcata Wastewater Treatment Plant

\section{Sustainability}

The second concern for ERD is to provide sustainability. The term sustainability was first used in 1980 in IUCN's World Conservation Strategy. The sustainability concept is arguably relevant to systems from the global to the local scale. Sustainable ecologically-based approaches to design are desirable but their application is not widely seen.

Sustainability reshapes environmental ethics, available technologies, planning techniques, and assessment criteria, which in turn influence environmental design disciplines. This approach suggests a need to contemplate spiritual aspects of sustainable design. A set of criteria is developed for sustainability to evaluate the environmental performance. In this context, sustainability becomes the key consideration in design.

If we propose to use ecological design of urban places to promote cultural change in the human relationship to the environment, then, we should be thinking about how to create physical settings with cues for sustainable behaviour.

The design of sustainable systems is consistent with ecological principles, which integrate human society with its natural environment for the benefit of both. There are many compelling reasons why environmental and resource problems should be placed in a dynamic perspective. It is important to provide sustainability by using moderate and efficient resource use. ERD strives for moderation and efficiency in resource use.

\section{The use of native plants (Naturalness)}

Naturalness provide to "sustainability" and "knowledge" about native plants. It also engages people and nature as it used to be. We can see the usage of native plants example 
on stormwater garden (Figure 9). It gives opportunity to people to have information about their native plants. Native trees and shrubs mimic the adjacent natural riparian areas, native plant communities and wildlife habitat. Natural water sources and planting zones will be considered when choosing plant material to minimize the need for irrigation.

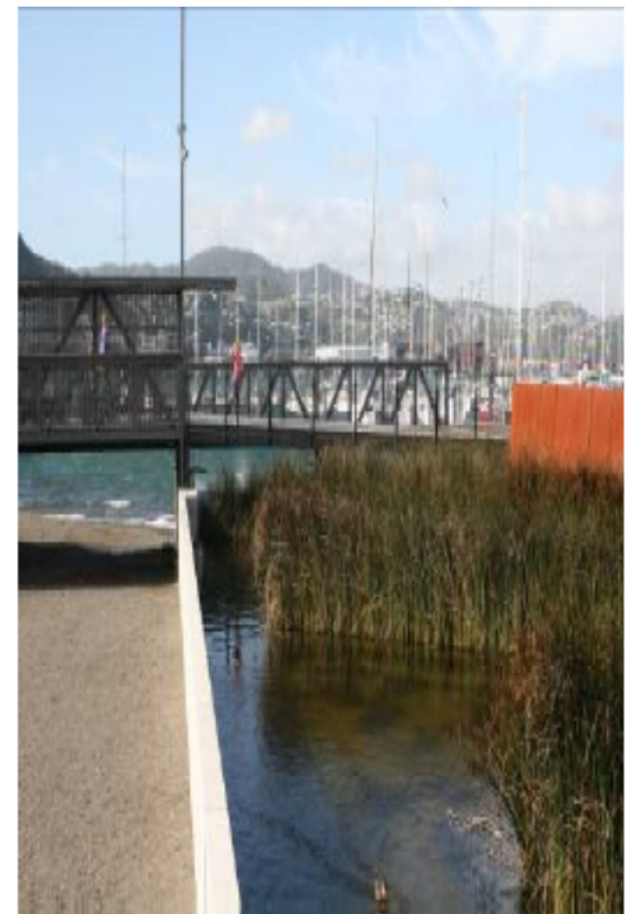

Figure 9. Stormwater management- the use of native plants

You can help stop the exotic plant invasion by using and nurturing native plants around your home and on your property. Native plants generally grow well and require less care than exotic species when grown on the proper soils under the right environmental conditions.

- $\quad$ Protective cover for most animals.

- $\quad$ Seeds, nuts, and fruits for squirrels and other mammals.

- $\quad$ Seeds, fruits, and insects for birds. add beauty to the landscape and preserve our natural heritage provide food and habitat for native wildlife

- serve as an important genetic resource for future food crops or other plant-derived products

If you enjoy observing nature, are concerned about the environment, or wish to make a long-term contribution to your community's ecosystem, then using native plants is a 
responsible, money-saving, long-term, positive investment to both your property and your community.

Landscaping with native plants improves the environment. Native plants are hardy because they have adapted to the local conditions. The native plants increase our connection to nature, help educate our neighbours, and provide a beautiful, peaceful place to relax.

The interest in the preservation and restoration of native plant communities increases as the public becomes more concerned about the environment. Native plants are valued for their economic, ecological, genetic, and aesthetic benefits in addition to the growing societal belief in their intrinsic value as living species.

\section{Observability}

It is relevant with visibility. People observe the design by hearing, listening and seeing. It makes awareness about the nature.

When ecological design incorporates "visibility" [23] and "observability" [24] it reveals ecological phenomena and processes and can be referred to as ERD.

\section{Multifunctionality}

Multifunctionality is the most important characteristics of this design strategy. It serves people multifunctional activities such as recreation, protection and education together. For instance, The Arcata Wastewater Treatment Plant combined with the Arcata Marsh and Wildlife Sanctuary has multiple uses, including wastewater treatment, recreation, wildlife habitat, education, and research.

Some people come to learn about the innovative wastewater treatment that enhances the community. Other people come to see the more than 270 species of birds that make use of the habitat provided by the Marsh [8]. Even more people come to exercise on the trails while enjoying the natural experience.

Multifunctionality is fundamental for sustainability. Multi-functionality is generally desirable, as it encourages efficient use of land, delivers wider public benefit and builds partnerships of user groups, leading to better stewardship. [25].

A designed land has many layers for visitors such as place for leisure activities, resting areas, conservation areas, fish and wildlife areas, sports activities and educational areas together. People gain social, environmental, economical advantage from multifunctional places.

\section{Legibility}

The design gives its mission to the visitor clearly. ERD purpose is "educate" and illumine". In this context, the messages have to be understandable. Effective design helps inform us about our place within nature. 
Legibility was interpreted as the understanding of how the landscape worked from its manifestation based on coherence between climate, soil, water and human occupation; or "understanding relationships between process and material, form and space" [26].

The spatial organization of design was utilized to clarify the ecological and cultural phenomena for people. People accompany the space by their senses. It gives people to create a spiritual connection with their environment and to have an educational consciousness.

\section{Ability to raise curiosity}

If the design does not take attention it can not to carry out its mission. To make people curious about the design shows its success. The perception is the most important element of design that its comprehensibleness and arouse curiosity.

It is important for people to "read" or "experienced" the ecological knowledge tried to given. This attempt is achieved by rising curiosity. If people wonder, they can learn the ecological awareness. Designers should enhance visitor's experience by encouraging interaction to interpret the ecological processes.

Effective design solutions or distinctive features are chosen as the general publics' ability to gain ecological information from their environment is limited. By using and revealing natural systems to spread consciousness and earn attention and care for our environment.

ERD overlap cultural needs and ecological processes to raise curiosity in visitors to explore and understand the complexity of the landscape.

\section{Conclusion}

ERD is a new approach in subdiscipline of design for landscape architecture, one where ecological process, the environment and the cultural awareness of people is a fundamental determinant of the design. Landscape architects should enhance visitor's experience by encouraging interaction to interpret the ecological processes. In this context, the ecological knowledge of them should be enough for interpretation of ecological processes on their designs. Also, it is important to be understood that the ecological phenomena helps people understand their environment and its cycles by their senses.

The present concept of ERD enriches the landscapes by incorporating visibility and observability. In this context, it reveals ecological phenomena and process. This process of revealing can only be successful if the environments created are visible, observable, legible, and have the ability to raise curiosity in visitors to explore and understand the complexity of the landscape.

In order to create a successful ecological design it is important to recognize and interpret the historic and cultural significance of the landscape. In other words, "ERD expands by hitching human habitat and their inevitable cultural determinants in to an environmentally inclusive vision" [16]. 
The Eco-Revelatory Design Exhibit, summarized in the 1998 special issue of Landscape Journal [1], clearly articulates an open challenge for landscape architects to work as environmental educators and to help heal the relationship between society and natural systems.

Explaining this new philosophy as distinctly different and complementary to ecological design, a more technical approach for designing with natural processes, ERD reveals the significant ecological aspects of a site and helps visitors build meaning and connection between the landscape and their own lives. In this sense, eco-revelatory designs are educative landscapes, pushing their visitors to think, gain perspective, and internalize new information [1].

ERD serves as a lens for reading the landscape's story. This design idea was resulted from environmental and ecological degradation, and the erosion of spiritual connections with the land.

Most of the projects have only one purpose: they are planned for recreation that ignores natural system usually or planned for protection. However, ERD is a multifunctional design that reveals natural systems and meets the cultural and ecological needs of human systems. By revealing natural systems earn people consciousness attention, and care for their environment. The basis for ERD is to create a landscape that is ecologically as well as culturally sustainable. It provides people educational and recreational opportunities.

The technology and the conditions of life break people's connections with nature. Landscape architecture can play a major role in the mission to bring together again nature and people and reveal the ecological processes by design.

\section{Author details}

Nurgül Konaklı Arısoy

Selçuk University, Agricultural Faculty, Department of Landscape Architecture, Turkey

\section{References}

[1] Brown B Harkness T Johnston D. Eco-Revelatory Design: Nature Constructed/Nature Revealed: Guest Editors' Introduction. Landscape Journal. 1998 Special Issue: x-xi.

[2] Eisenstein W. Ecological design, urban places and the culture of sustainability: Can citybuilding foster a culture of sustainability? Retrieved 8/23/2009, from SPUR. 2001. http://www.spur.org/publications/library/article/ecologicaldesign09012001

[3] Brown B. Holding moving landscapes. Landscape Journal 1998 (Special issue):53-68.

[4] Ndubisi F.. Ecological planning: a historical and comparative synthesis. Johns Hopkins University Press, Baltimore; 2002

[5] Cox Von Ins R E. Designing for Interpretation: Nanny's Mountain Park, Master Of Landscape Architecture. Maureen Grasso Dean of the Graduate School The University of Georgia , Athens; 2006. 
[6] McHarg I L. Design with Nature. Doubleday/Natural History Press, Garden City, NJ; 1969

[7] Forman R T. The Missing Catalyst: Design and Planning with Ecology Roots. Washington Covelo London:Island Press; 2002

[8] The Ashford Borough Council. 2008

[9] http://www.landscapeonline.com/research/article/15739

[10] Opdam P Verboom J and Reijnen R.. Landscape cohesion assessment: determining the conservation potential of landscapes for biodiversity (submitted); 2002

[11] Nassauer J I Opdam P.. Design in science: extending the landscape ecology paradigm, Landscape Ecol, Springer 2008: 23:633-644, DOI 10.1007/s10980-008-9226-7

[12] Turner M G. Landscape ecology: The effect of pattern on process. Annu. Rev. Ecol. Syst 1989: 20: 171-197.

[13] IALE Executive Committee, 1998. IALE Mission Statement. IALE Bulletin 16:1

[14] Ahern J. Integration of landscape ecology and landscape design: An evolutionary process. Edited by J. A. Wiens and M. R. Moss. International Association for Landscape Ecology, Guelph, Ontario, Canada.Landscape Ecology 1999: 119-123.

[15] Lyle J T. Regenerative Design for Sustainable Development. New York: John Wiley \& Sons;1994.

[16] Mozingo L A. The Aesthetics of Ecological Design: Seeing Science as Culture Landscape Journa,1 Spring, 1997 (16) 1 46-59 DOI: 10.3368/lj.16.1.46

[17] Farina A. Principles and methods in landscape ecology. London: Chapman \& Hall; 1998

[18] Deshpande A M. Design Process to Integrate Natural and Human Systems, Landscape Architecture, State University, Ms Thesis, Blacksburg, VA.; 2003

[19] Lyle J T. Design for human ecosystems. Landscape, land use, and natural resources. New York: Van Nostrand Reinhold Company Inc ; 1985

[20] LaGro J A. Site analysis. Linking program and concept in land planning and design. New York: John Wiley and Sons: 2001

[21] Nassauer J I. The appearance of ecological systems as a matter of policy. Landscape Ecology 1992: (6) 239-250

[22] Zhang B. Technicalization of Environmental Aesthetics and a Resolution of Spirituality, Architecture, Culture, and Spirituality Symposium. JUne29-July 1 2011, Serenbe, Georgia, USA

[23] Hough M. Cities and Natural Process, London: Routledge; 1995

[24] Thayer R L. The experience of sustainable landscapes. Landscape Journal 1989: 8 (2):101-110.

[25] Selman P. Community Essay. Department of Landscape, University of Sheffield, Crookesmoor Building, Conduit Road, Sheffield S10 1FL United Kingdom, Planning for landscape multifunctionality, Sustinnability: Science, Practice \&Policy 2009: 5 (2)

[26] Spirn A W. The language of landscape. New Haven and London, Yale University Press; 1998. 
[27] Lyle J T. Regenerative Design for Sustainable Development. New York: John Wiley \& Sons; 1994 